\title{
Política Nacional de Humanização como aposta na produção coletiva de mudanças nos modos de gerir e cuidar
}

Dário Frederico Pasche ${ }^{1}$

\section{Introdução}

Colocar a humanização da saúde em debate é uma atitude que nos convoca à reflexão, à crítica generosa em direção da construção de um SUS que seja cada vez mais potente para expressar o interesse público e o bem comum.

Colocar a Política de Humanização do SUS em questão é movimento de abertura. Abrir-se para alteridades, mas também incidir sobre quem força a passagem; dar passagem e abrir passagem; influenciar e deixar-se influenciar. Propor-se a sínteses, a deslocamentos, à construção de percepções comuns, permitidos pelo encontro com a diferença. Mas também de ratificação de diferenças, de discordâncias e de não acordos.

Coragem, generosidade, dar passagem, permitir-se tocar pela diferença para diferir, tudo isto com o propósito de aprimorar o SUS. Esta é uma aposta éticopolítica que une muitos sujeitos que têm por intento, com suas reflexões e ações práticas, qualificar serviços e práticas de saúde em defesa da vida, melhorando nossa experiência de viver em sociedade.

Falar sobre a humanização das práticas de saúde coloca, antes de tudo, a necessidade de se fazerem algumas marcações sobre a própria constituição da política pública de saúde, buscando compreender o sentido de suas apostas. A partir desta compreensão é possível, então, localizar o papel e ação da Política de Humanização do SUS (PNH), verificando as razões estratégicas de sua formulação e sua importância na construção do SUS como política inclusiva e resolutiva. Estes são os propósitos deste texto.

\section{SUS: reforma ética, social e cultural no sistema, serviços e práticas de saúde}

A Constituição Federal de 1988 estabeleceu uma nova base jurídico-legal para a política de saúde, definindo a saúde como um direito de qualquer cidadão, logo, um dever do Estado. Além disto, no Brasil, passou-se a compreender que saúde corresponde a um enunciado mais amplo que a ausência de doenças e mais concreto que a idéia de bem-estar. Saúde passou a ser compreendida como produção social, resultando, então, de complexas redes causais que envolvem

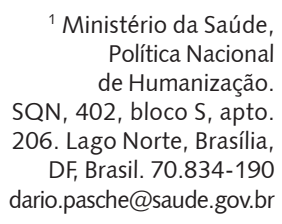

${ }^{1}$ Ministério da Saúde, Política Nacional de Humanização. SQN, 402, bloco S, apto. 206. Lago Norte, Brasília, DF, Brasil. 70.834-190 dario.pasche@saude.gov.br 
elementos sociais, econômicos e culturais que se processam e se sintetizam na experiência concreta de cada sujeito singular, de cada grupo em particular e da sociedade em geral.

Para que o Estado cumpra seu dever constitucional na saúde se estabeleceu, então, que é necessária a implementação de políticas sociais e econômicas justas, que distribuam renda e dignifiquem a vida, pois a saúde resulta dos modos de vida, que definem a qualidade de vida, que é tanto melhor quanto maior for a capacidade da sociedade de produzir regras em que prevaleçam o interesse e o bem comum.

Saúde como produção social significa reconhecer que quanto mais desigual for a distribuição das riquezas, quanto mais precário for o acesso dos grupos sociais aos bens de consumo e a políticas públicas redistributivas, mais serão heterogêneos e injustos os padrões de adoecimento e mortalidade.

Mas a produção de "vida boa" por regras sociais mais justas não anula a presença de agravos, doenças e riscos para a saúde, senão altera sua natureza. Assim, a organização de sistemas de saúde é imprescindível para que as sociedades produzam saúde, que devem, então, estruturar e organizar o setor, que tem papel importante na qualificação da vida da população.

Dessa forma, produção de saúde decorre de dois macrocomponentes que se influenciam mutuamente: (1) a organização de políticas públicas que distribuem renda e (2) a garantia de acesso a serviços e ações integrais de saúde. Ações integrais correspondem, entre outros, à combinação e articulação entre medidas de promoção e prevenção com as de cura-reabilitação, cuja sinergia deve resultar na oferta, aos cidadãos e à sociedade, de práticas de saúde resolutivas e de qualidade.

A garantia de acesso aos serviços de saúde no Brasil é assegurada pela organização de um sistema descentralizado de saúde. Descentralização corresponde à criação de estratégias para a responsabilização sanitária compartilhada entre as três esferas de governo para que, preferencialmente, os municípios organizem, de forma sustentável e em cooperação com demais gestores, redes de atenção integral à saúde. A base desta rede, segundo o princípio da integralidade, é a atenção primária, que organizada em todo território nacional, tem, por tarefa, a viabilização de uma orientação simples, mas muito significativa para a construção da efetividade das práticas: todo cidadão tem o direito a uma equipe que cuide dele, com a qual ele estabelece fortes vínculos terapêuticos, sustentáculo de processos de corresponsabilização no cuidado em rede.

Outra diretriz da política de saúde no Brasil é a participação cidadã. Ou seja, o sistema e os serviços de saúde devem ser cogeridos, o que requer, entre outros aspectos, a inclusão de novos sujeitos nos processos de decisão na saúde, sobretudo segmentos de usuários, que por meio de conselhos e conferências - arranjos de cogestão do Estado - encontram espaços de vocalização de interesses e necessidades, os quais passam a compor - superados os processos de negociação -, organicamente as políticas de saúde.

A participação cidadã em saúde é espaço de abertura para a construção, com o conjunto da sociedade, de processos de corresponsabilização na gestão da política de saúde, sem com isto desresponsabilizar o Estado de suas funções essenciais. A construção de espaços coletivos e arenas decisórias para o processamento de interesses na formulação e gestão de políticas públicas é uma estratégia importante de democratização do Estado e do acesso aos serviços de saúde.

A inscrição da nova base legal do SUS resultou de acúmulo de forças no interior da sociedade brasileira em um determinado tempo histórico, impulsionadas pelo desejo de democratização das relações sociais e econômicas, de enfrentamento de iniquidades no acesso aos serviços de saúde e de combate à privatização das políticas de saúde. A criação do SUS só foi possível pela construção de um movimento pela reforma sanitária, suprapartidário e plural, que reuniu segmentos sociais muito amplos em defesa de profundas mudanças no sistema e serviços de saúde, reafirmando o direito do povo a uma saúde universal e de qualidade.

O marco jurídico-legal da política de saúde brasileira, substanciado da definição ético-política de que saúde é direito de qualquer um, tem se apresentado como uma importante abertura e possibilidade de se reformar o sistema de saúde do país. Contudo, a inscrição legislativa não é uma garantia per si para a transmutação de valores e de práticas no sistema de saúde, e a base jurídico-legal do SUS se apresenta, sobretudo, como orientação ética, política e organizacional para se construir um novo sistema de saúde, pautado na justiça social, na equidade e na solidariedade. Uma aposta e um horizonte ético e utópico.

A construção de uma nova realidade jurídica não garante a produção de mudanças na velocidade 
desejada, pois a organização dos serviços de saúde é permanentemente atravessada por interesses múltiplos de grupos sociais, forças instituintes que tensionam e provocam mudanças nas regras e nas práticas de saúde. Nem mesmo a direção das mudanças está assegurada, e a disputa entre interesses antagônicos - como privatização e o bem comum, teses universalistas ou restritivas de acesso, a oferta de práticas integrais ou cardápios básicos, entre outros -, se depura e se define no jogo da política.

Nestes vinte anos de SUS, nestes vinte anos de luta, muitos avanços têm sido registrados e, certamente, o Brasil está incluído entre as nações que consideram a saúde como um valor social substantivo; e este entendimento tem tomado forma na construção de um robusto sistema público de saúde, a maior organização sanitária da América Latina. Nestes vinte anos de SUS, reorganizou-se a rede de atenção, solidificando-a a partir do fortalecimento de estratégias de atenção básica; ampliou-se o acesso das pessoas aos serviços; o território nacional foi integrado por meio de redes de atenção municipalizadas e regionalizadas; ampliou-se a quantidade, a diversidade e a qualidade dos trabalhadores da saúde, avançando-se na organização do trabalho em equipe; investiu-se em pesquisa e desenvolvimento científico e tecnológico tanto de equipamentos quanto de insumos estratégicos, entre os quais vacinas e medicamentos; foram desenvolvidos sistemas de informação e de gestão, que permitiram monitorar resultados e melhorar o processo de tomada de decisão. Além disto, o SUS passou a contar com vários programas e políticas reconhecidos como de excelência, a exemplo dos programas de imunização e de prevenção de DST/Aids, entre outros.

Mas estes avanços são do tamanho dos desafios que o SUS ainda tem pela frente: superação da cultura sanitária biomédica, que associa saúde a ação médica e acesso a remédios e hospital, concepção que permite a medicalização da vida; aporte insuficiente de recursos para financiar as ações de saúde (subfinanciamento do SUS); iniquidades no acesso; vazios assistenciais em muitos territórios; inexistência operacional de rede de atenção, o que dificulta a continuidade dos tratamentos; ineficiência da atenção básica, ainda entendida como ação direcionada para população pobre; forte presença da cultura hospitalocêntrica e de interesses privados, corporativos e político-partidários na definição de políticas de saúde e na organização de serviços de saúde (privatização); cultura federativa subdesenvolvida que leva à competição por recursos e à baixa responsabilização sanitária entre municípios e destes com os estados; baixa capacidade de ordenamento dos processos de formaçãa de trabalhadores às necessidades do sistema de saúde, sobretudo nos programas de graduação e residência das carreiras da saúde; ausência de uma "carreira SUS" para trabalhadores da saúde, entre outros.

Ou seja, o sistema de saúde brasileiro, percorridos vinte anos, traz ainda fortes marcas, em sua estrutura e organização, de concepções que se hegemonizaram, sobretudo, a partir de meados da década de 1960 (Oliveira, Teixeira, 1986), que instituíram um sistema privado, assistencialista e essencialmente focado para a intervenção sobre doenças, portanto desprovido de capacidade de colocar a vida, a produção de saúde em primeiro lugar, de pôr o humano como centro da ação da política de saúde.

\section{Política de Humanização: a experiência do SUS que dá certo como estratégia de enfrentamento de problemas e desafios que ainda marcam a política pública de saúde brasileira}

É necessário compreender que os avanços conseguidos e a presença ainda marcante de desafios no SUS se devem à própria dinâmica das políticas públicas, atravessadas que são por interesses políticos e econômicos que se (re)atualizam sistematicamente. As políticas públicas de saúde devem ser analisadas e avaliadas à luz de seus contextos históricos, políticos e institucionais, que permitem compreender os padrões de capilaridade e seletividade da máquina de Estado à ação de grupos de interesse. Além disso, a efetividade das políticas de saúde decorre da capacidade do próprio setor saúde de lidar com suas questões organizativas e de gestão, entre as quais a de acumular forças para alterar os modos de atenção, fazendo prevalecer interesses do bem comum, do coletivo.

A análise da construção social, política e institucional do SUS faz com que ele seja compreendido como um movimento ambíguo, apresentando-se, ao mesmo tempo, como avanço na universalização e qualificação do acesso, e como conservação de contradições que marcaram o sistema de saúde 
brasileiro como um dos mais injustos do planeta. O SUS, em um só tempo, é mudança e conservação (Pasche et al., 2006).

A Política de Humanização (Brasil, 2007) se apresenta e se constrói exatamente nesta dobra, neste duplo reconhecimento: há um SUS que dá certo e há problemas e contradições que necessitam ser enfrentados.

A PNH considera que existem construções e experimentações desenvolvidas na política pública de saúde em muitos planos, âmbitos e lugares que permitem afirmar que se avançou tanto na construção de novos modos de gerir, como na constituição de novos modos de cuidar, em conformidade com a base discursiva do SUS.

Foi a partir da verificação, escuta, análise e síntese deste SUS que dá certo que se produziram tanto os princípios, método, diretrizes e os instrumentos de ação, os dispositivos da PNH (Brasil, 2007). Assim, a Política de Humanização não parte senão de próprios acúmulos de experiências de uma grande quantidade de sujeitos coletivos espalhados por muitos lugares deste país, que atuam e produzem inovações em uma vasta gama de serviços, em "espaços do cuidado" e nos "espaços de gestão".

Esta opção metodológica tem efeito de positivação sobre o SUS, pois embora considere os problemas e os desafios do SUS, não parte deles, e sim da localização de elementos substantivos das experiências que permitiram superar desafios, para propor modos de fazer e direção aos processos de mudança na saúde. Este movimento de positivação potencializa a ação de sujeitos e coletivos sociais, pois não partindo do negativo extrai efeitos de amplificação e de contágio para a mudança. Assim, não se tomam os problemas senão para enfrentá-los, cujas ferramentas discursivas e concretas de ação se constroem a partir da positividade das experiências.

Esta é uma sensível e radical diferença, um importante deslocamento para o enfrentamento das contradições do SUS, pois ali onde se anunciava o problema (os modos de gerir e de cuidar), onde se localizavam as dificuldades mais radicais (ação autônoma dos sujeitos) e a impossibilidade da construção de planos de ação comum (relação entre sujeitos com interesses e necessidades não coincidentes) é que se vai buscar a força e a possibilidade da produção da mudança. Ação de contágio e afecção pelo SUS que dá certo, que "dá certo" como modo de fazer e como direção ético-política.

Das experiências concretas nos serviços e práticas do SUS, da análise de sua construção, é que a PNH extrai, então, suas construções discursivas e práticas. Seu arcabouço organizativo articula, de forma orgânica, princípios, método, diretrizes e dispositivos.

Das experiências do SUS que dá certo, a Política de Humanização tomou, então, uma trinca de princípios, articulados e indissociáveis:

- a inseparabilidade entre modos de gestão e de atenção, compreendendo que são mutuamente influenciados e determinados;

- transversalização de saberes, poderes e afetos na ação cotidiana dos serviços e das práticas de saúde, fomentando deslocamentos subjetivos e a produção de planos de ação comum sem, contudo, borrar a ponto de negar especificidades, senão colocando-as em relação, em rede, para diferir;

- aposta na autonomia e protagonismo dos sujeitos, que em relação e guiados por orientações éticas - também construções históricas - são capazes de acionar vontade e desejo de mudança, construindo redes de corresponsabilização.

Estes princípios - de onde se parte - convocam a reflexão de como fazer para que eles se inscrevam de forma efetiva nas práticas de saúde, ou seja, exigem que se definam modos de fazer. Assim, está colocada a questão sobre o método, caminho a ser percorrido para a construção de novas realidades. As experiências dos SUS que dá certo informam sobre a inclusão, ou seja, apontam para a criação de estratégias de inclusão de sujeitos nos processos de produção das próprias mudanças. A PNH toma este princípio, amplificando-o e qualificando-o como método da tríplice inclusão:

- inclusão de todos os sujeitos nos arranjos, processos e dispositivos de gestão, na clínica e na saúde coletiva. Incluir implica a construção de espaços coletivos para pôr em contato, em relação, sujeitos para que, no encontro, produzam entendimentos e ações comuns. Em outras palavras: promover o cotejamento de diferenças entre sujeitos para a construção de processos de corresponsabilização na gestão e no cuidado e pelos encargos que daí derivam; 
- inclusão de coletivos, redes e movimentos sociais. O SUS, como aposta na mudança dos modos de gerir e de cuidar na saúde, se solidifica e tende a ser mais estável se encarnado como experiência coletiva, como síntese da pluralidade de interesses e necessidades heterogêneos. O fomento e a produção de redes sociais tanto na condução e gestão da coisa pública, como na efetivação do cuidado clínico e de saúde coletiva, ampliam a sustentação de mudanças na política pública (sempre síntese de interesses plurais e heterogêneos) e a construção de novos sujeitos nos processos de produção do cuidado (corresponsabilização) e da saúde coletiva (ação coletiva sobre territórios, na perspectiva da produção ampliada de saúde e da cidadania);

- inclusão de analisadores sociais, da perturbação emergente da inclusão de sujeitos e coletivos sociais nos arranjos e dispositivos de gestão e do cuidado (individual e coletivo). Esta inclusão talvez seja a mais radical na $\mathrm{PNH}$, pois o encontro de alteridades não pode ser compreendido apenas como abertura à participação em direção aos usuários e trabalhadores para uma maior aderência a prescrições heterônomas, ou para simples melhorias nos processos de gestão convencional das organizações. Incluir o outro implica atitude generosa que suscita alteração nas relações de poder entre os sujeitos. Alterar relações de poder requisita deslocamentos e ressignificação dos lugares e posições que se ocupam na relação com o outro na perspectiva da produção de corresponsabilização; o que exige, por sua vez, relativizar construções prévias ao encontro, para nele produzir ação comum. Isto não quer dizer abrir mão da tradição, da ciência, de mandatos sociais, mas utilizá-los como recursos para a coprodução de saúde. Incluir o outro e incluir a perturbação desta inclusão impõe a necessidade de lidar de forma menos paranóica com a diferença; e a lidar com/e gerir conflitos, entendidos como espaços de abertura, de passagem do outro, condição necessária para a produção de mudança.

O método da tríplice inclusão se apresenta, então, como estratégia de construção de processos coletivos, uma vez que propicia o cotejamento, em espaços públicos, de posições não necessariamente coincidentes - portanto expressão do coletivo, sempre plural -, para a produção do comum na diferença.

Os princípios da humanização e seu método da tríplice inclusão, todavia, não podem estar desprovidos de orientações éticas, clínicas e políticas, as quais marcam, de forma geral, a direção da ação, da coprodução de sujeitos e de saúde.

A PNH aponta para um conjunto de diretrizes, as quais sinalizam direção para as construções coletivas. São elas:

- acolhimento, compreendido como atitude de abertura à recepção de necessidades de saúde que se expressam na forma de demandas para os serviços e profissionais da saúde. Acolher requer a construção de respostas satisfatórias às necessidades, independentemente da lógica de organização dos serviços, que devem ter o acolhimento como diretriz norteadora de sua forma de funcionamento. $\mathrm{O}$ acolhimento é uma diretriz ética, portanto inegociável e, por isto, uma direção fundamental para a construção de redes de atenção, redes de cuidado;

- gestão-participativa e cogestão, que são expressões da democratização das instituições de saúde e das relações entre os sujeitos. Democracia pressupõe abertura, criação de espaços coletivos e sua substantivação, permitindo o cotejamento de diferenças para a produção compartilhada de corresponsabilidade na gestão e no cuidado;

- ampliação da clínica, cujos sentidos principais vão em direção à ampliação do diálogo e da interferência dos sujeitos em relação na definição de contratos (de gestão e clínicos); inclusão de alteridades implica acolher a diferença na contratualização de tarefas (ampliação das ofertas de gestão, de cuidado, de práticas etc); personalização do cuidado e dos modos de gestão, considerando que toda relação clínica e de gestão é sempre marcada por interesses, desejos e necessidades de sujeitos que se atualizam e se singularizam nesta relação;

- fomento de redes de valorização do trabalho e do trabalhador. Valorizar o trabalhador (e seu fazer, suas construções) implica, pelo menos, três grandes movimentos: (1) inclusão do trabalhador nas definições sobre o funcionamento da organização de saúde, ou seja, descentralização do poder de decisão sobre o cotidiano das instituições; (2) construção e viabilização de melhorias nas condições concretas de trabalho, como remuneração, ambiência, acesso a insumos tecnológicos adequados para a 
produção de saúde etc; e (3) pautar e interferir sobre os elementos e fatores que interferem na produção da saúde do trabalhador, incluindo os trabalhadores no mapeamento e controle de riscos, por exemplo;

- defesa dos direitos dos usuários: o SUS reconhece que os usuários são portadores de direitos na saúde, os quais perpassam tanto a gestão do sistema (sistema colegiado de gestão do SUS e de seus serviços), como a relação clínica e da saúde coletiva. Reconhecer direitos requer a percepção do estatuto de sujeitos das alteridades (individuais e coletivas), cujas referências e patamares foram consensuados e pactuados como relações sociais. Os direitos dos usuários - estatuto ético-político devem (1) pautar e marcar a organização dos processos de trabalho e orientar as práticas clínicas e de saúde coletiva. Além disto, pressupõe a (2) construção de contratos de corresponsabilização, síntese entre "mandato social dos trabalhadores da saúde" e os "direitos dos usuários", polos antinômicos. Dessa forma, a tensão entre direitos e deveres dos usuários toma o lugar da construção compartilhada do cuidado, que significa reconhecer direitos e mandatos sociais, os quais se atualizam na construção de cuidado singular.

- ambiência: o trabalho e o cuidado em saúde acontecem, entre outros, em espaços das organizações da saúde. Estes espaços de trabalho nem sempre respondem aos interesses imediatos dos usuários e trabalhadores, obedecendo, também, a outros interesses e lógicas institucionais multiinteressadas. A produção de sujeitos e de saúde decorre, também, da organização dos espaços de trabalho, os quais devem refletir princípios e diretrizes do SUS, da humanização da saúde. Humanização significa pôr os sujeitos, as pessoas, em primeiro lugar na construção do cuidado e da gestão; e, nesta perspectiva, a reconstrução dos espaços de trabalho deve ser um exercício coletivo para (1) adequar o ambiente de trabalho às diretrizes de reorganização dos processos de trabalho (em equipe e cogeridos) e (2) responder aos interesses dos trabalhadores da saúde e dos usuários (ambiente acolhedor, agradável, como dispositivo de produção de bem-estar e de saúde);

- construção de memória dos processos de mudança: política da narratividade - novos modos de fazer requisitam novos modos de narrar, eles mesmos produtores dos sentidos das mudanças. $\mathrm{A}$ construção de sentido nas mudanças na produção de saúde, tarefa de sujeitos e coletivos, é fundamental para a sustentação de princípios ético-políticos na reorganização dos serviços e práticas de saúde. Perceber-se construtor da história, construtor de obras (Campos, 1997) é apoderar-se da condição de sujeito que cria o mundo e nele se reinventa. Isto significa reconhecer, como disse Freire (1996, p.19), "que somos seres condicionados, mas não determinados. Reconhecer que a História é tempo de possibilidade e não de determinismos, que o futuro [...] é problemático e não inexorável". Fazer os sujeitos se reconhecerem construtores da história pela narrativa de suas próprias trajetórias, é estratégia de desalienação, de produção de novos sujeitos e da construção de possibilidades de superação dos novos desafios que nascem da própria construção de políticas públicas.

O exercício destas diretrizes, ressalta-se, deve sempre interrogar sobre modos de fazer, o que, na perspectiva da $\mathrm{PNH}$, implica a inclusão dos sujeitos, de coletivos, de analisadores sociais e na produção multi-interessada de novas realidades.

A PNH reúne um conjunto de princípios metodológicos que a afirma, então, como um modo de fazer, um modo para se enfrentar problemas dos serviços e práticas de saúde. Este modo de fazer considera princípios e diretrizes, orientações gerais para o processo de mudança, os quais são experimentados por meio de arranjos de trabalho (dispositivos). Por dispositivos entende-se não uma prescrição, senão também formas de organização dos processos de trabalho, que se atualizam e tomam sentido em cada uma das experiências singulares, ou seja, são moldáveis à experimentação dos sujeitos e seus contextos político-institucionais.

\section{A Política de Humanização como oferta para se lidar com problemas e contradições que persistem no SUS}

Outro elemento do qual parte a PNH - além das produções positivas do SUS - é a existência, ainda como marca importante da política pública de saúde, de um conjunto de problemas e contradições, cuja presença indica que há sinais visíveis de crise na saúde brasileira (Campos, 2007). Esta crise é tanto 
apontada, de uma parte, pela sociedade como um todo e por usuários em particular, que denunciam: o descaso com o atendimento, a descontinuidade nos tratamentos, longas esperas em filas, pagamentos "por fora", entre outros problemas, que, muitas vezes, ganham a adjetivação de desumanização do atendimento.

De outra parte, os trabalhadores da saúde também têm apontado para uma série de limitações no SUS, quer seja em relação às condições concretas de trabalho - como a baixa remuneração, a inexistência de planos de carreiras e salários - que levam à precarização, à exploração e à desvalorização do trabalho, quer seja em relação aos modos de organização do processo de trabalho, em geral tendentes à expropriação dos trabalhadores dos processos decisórios.

Estes problemas apontados por usuários e trabalhadores (no exercício de atividades fins e, também, os que ocupam lugares na gestão) são do estatuto da complexidade, pois incide sobre sua gênese um conjunto de elementos de vários planos, os quais se engendram mutuamente, construindo redes causais complexas. Para o enfrentamento destas realidades hipercomplexas, a PNH aponta para a necessidade do exercício de método, cuja experimentação coloca sujeitos em contato e em relação para que, de forma coletiva e tomando por referências princípios ético-políticos e acúmulos do SUS que dá certo, construam soluções singulares.

Assim, a PNH se apresenta como a expressão de um SUS que dá certo, cuja síntese organiza um conjunto de conceitos e ferramentas para a superação de problemas e contradições que ainda permanecem como marcas dos serviços e práticas de saúde.

A Política de Humanização não pode, desta forma, ser apenas um valor, algo sobre o qual se inspirariam e se sustentariam práticas, senão deve informar sobre a produção de mudanças concretas (Barros, Passos, 2005) que reafirmam a humanização como um valor. Ou seja, a humanização se assenta na dobra valor - prática social.

A experimentação e consolidação de políticas públicas mais equitativas, inclusivas e solidárias é uma tarefa civilizatória porque aposta na capacidade de enfrentamento e contorno de contradições sociais, cuja superação faz emergir novas consciências, novos patamares éticos e políticos, sustentáculos para a qualificação da vida e da experiência em sociedade.

É tarefa para os próximos vinte anos do SUS manter vivas e fortalecidas, manter pulsantes as forças sociais e políticas que criaram e sustentaram a reforma sanitária brasileira. Radicalizar o interesse coletivo na ação do Estado, afirmando a natureza pública das políticas sociais, convoca a sociedade civil a "jogar o jogo da política", a disputar as orientações na condução da coisa pública, ação que se faz em todos os espaços singulares da micropolítica, mas também em outros planos, no interior e nos limites da máquina do Estado.

Este é o papel e a função estratégica da Política de Humanização: manter pulsante, no SUS, em cada uma de suas políticas, o espírito e ação solidários, a construção do bem comum e a luta intransigente contra a cooptação deste sentido pela máquina do Estado em geral, por qualquer instituição em particular, ou qualquer grupo singular.

\section{Referências}

BARROS, R.B.; PASSOS, E. Humanização na saúde: um novo modismo? Interface Comunic., Saude, Educ., v.9, n.17, p.389-94, 2005.

BRASIL. Ministério da Saúde. Secretaria de Atenção à Saúde. Núcleo Técnico da Política Nacional de Humanização. HumanizaSUS: documento base para gestores e trabalhadores do SUS. 4.ed. Brasília: Editora do Ministério da Saúde, 2007.

CAMPOS, G.W.S. Reforma política e sanitária: a sustentabilidade do SUS em questão? Cienc. Saude Colet., v.12, n.2, p.301-6, 2007.

CAMPOS, G.W.S. Subjetividade e administração de pessoal: considerações sobre modos de gerenciar o trabalho em equipes de saúde. In: MERHY, E.; ONOCKO, R. (Orgs.). Agir em Saúde: um desafio para o público. São Paulo: Hucitec, 1997. p.229-66. 
FREIRE, P. Pedagogia da autonomia: saberes necessários à prática educativa. São Paulo: Paz e Terra, 1996.

OLIVEIRA, J.; TEIXEIRA, S.F. (Im)previdência social: 60 anos de história de Previdência no Brasil. Petrópolis: Vozes, 1986.

PASCHE, D.F. et al. Paradoxos das políticas de descentralização de saúde no Brasil. Rev. Panam. Salud Publica, v.20, n.6, p. 416-22, 2006.

A construção do Sistema Único de Saúde (SUS) se inscreve como processo de luta para a afirmação da saúde como um valor social substantivo da sociedade brasileira. O SUS tem produzido uma reforma na saúde ensejando, ao mesmo tempo, mudanças éticas, culturais e políticas. Em duas décadas de experimentação o SUS tem realizado mudanças e conservação de características que marcaram o Brasil como um dos países com maior iniquidade no acesso. A Política Nacional de Humanização (PNH) se constrói no duplo reconhecimento de que há um SUS que dá certo e que há problemas e contradições que necessitam ser enfrentados e, para tanto, organiza um conjunto de conceitos, métodos e dispositivos para o enfrentamento de problemas que ainda permanecem como marcas dos serviços e práticas de saúde.

Palavras-chave: Humanização. Políticas Públicas de Saúde. Sistema Único de Saúde. Cuidado em Saúde. Política Nacional de Humanização.

\section{National Humanization Policy as a bet for collective production of changes in management and care methods}

The construction of the Unified Health System (SUS) has been registered as a process of striving to affirm healthcare as a substantive social value for Brazilian society. SUS has produced reforms in the healthcare sector, while at the same time giving rise to ethical, cultural and political changes. Over two decades of experimentation, SUS has accomplished changes and conserved characteristics that have marked out Brazil as one of the countries with greatest inequality of access. The National Humanization Policy (PNH) has been constructed with the double recognition that SUS works well in some respects but that, in other respects, there are problems and contradictions that need to be addressed. For this, the PNH has organized a set of concepts, methods and devices to face up to the problems that still mark out the healthcare services and practices.

Keywords: Humanization. Public healthcare policies. Health System. Healthcare. National Humanization Policy.

\section{Política Nacional de Humanización como apuesta en la producción colectiva de cambios en los métodos de gestión y cuidado}

La construcción del Sistema Único de Salud (SUS) en Brasil se inscribe como proceso de lucha para la afirmación de la salud como un valor social substantivo de la sociedad brasileña. EI SUS ha producido una reforma en salud dando oportunidad, al mismo tiempo, a cambios éticos, culturales y políticos. Eh dos décadas de experimentación, el SUS ha realizado cambios y oonservación de características que habían convertido Brasil en uno de los paises con menor equidad en el acceso. La Política Nacional de Humanización (PNH) se construye en el doble reconocimiento de que hay un SUS eficiente y de que hay problemas y contradicciones que es necesario afrontar $y$, para tanto, organiza un conjunto de conceptos, métodos y dispositivos para afrontar problemas que permanecen aún como marcas de los servicios y prácticas de salud.

Palabras clave: Humanización. Políticas Públicas de Salud. Sistema Único de Salud. Cuidado en Salud. Política Nacional de Humanización. 